\title{
CLIMATIC OPTIMUM AS A FACTOR OF THE ECONOMIC CRISIS OF STEPPE NOMADS IN THE $4^{\text {th }}$ CENTURY AD ${ }^{1}$
}

\author{
Mikhail V. Krivosheev \\ Volgograd State University, Volgograd, Russian Federation
}

\begin{abstract}
Aleksandr V. Borisov
Institute of Physical-Chemical and Biological Problems of Soil Science, Russian Academy of Sciences, Pushchino, Russian Federation
\end{abstract}

\begin{abstract}
Introduction. Archaeological sites of the $4^{\text {th }}$ century AD absent on most of the area of the Late Sarmatian culture. This may be both due to the difficulties of their identification and absence of chronological indicators and due to migrations of nomads from the steppe zone. Perhaps unfavorable climatic conditions for nomadic cattle breeding affected the decrease in the number of nomadic population in the $4^{\text {th }}$ century AD. Methods and materials. The paleosoil data allow reconstructing the ecological situation in dry and desert steppes in the first centuries AD. The initial stage of the Late Sarmatian era (the late $2^{\text {nd }}$ - the early $3^{\text {rd }}$ centuries AD) was marked by arid conditions with cold winters with little snow, which were favorable for cattle breeding in the steppe zone. In the late $3^{\text {rd }}$ century and at the turn of the $3^{\text {rd }}-4^{\text {th }}$ centuries, the processes of humidization began - an increase in climate humidity, which favorably affected the ecological situation in the steppe: high grass, area watering. Such situation provided successful livestock grazing in summer. However, in winter, an increase in humidity led to heavy snowfalls and snowstorms, an increase in snow cover, frequent winter thaws, rain, fog, that were replaced by periods of cooling. At this time, grass icing and ice crust formation occured. Analysis. In those conditions, the number of days, when cattle grazing was impossible, increased. As a consequence, there was weakening and disease of the livestock, until the complete loss of the herd. This was followed by the decrease of population. Results. The humidization processes primarily affected the Southern Urals and in the final of the $3^{\text {rd }}$ century reached the VolgaDon steppes. This could be the reason for the outflow of the Late Sarmatian population from the Southern Urals to the Volga regions. In the $4^{\text {th }}$ century AD, the steppes from the Urals to the Lower Don were practically depopulated. The beginning of the humid period, which was unfavorable for the nomadic economy, had a positive effect on settled agricultural societies. The Early Alanian culture of the Central Caucasus demonstrates the dynamics of active development throughout the Late Sarmatian period, including in the $4^{\text {th }} \mathrm{c}$. AD. The duration of this humid period is difficult to estimate, however, in the Hun Epoch, steppes remained almost uninhabited, as evidenced by the small number of sites of this time.
\end{abstract}

Key words: Sarmatians, Late Sarmatian culture, soil science, environmental situation, aridization, humidization.

Citation. Krivosheev M.V., Borisov A.V. Climatic Optimum as a Factor of the Economic Crisis of 2 Steppe Nomads in the $4^{\text {th }}$ Century AD. Vestnik Volgogradskogo gosudarstvennogo universiteta. Seriya 4. Istoriya. $\overrightarrow{\tilde{2}}$ Regionovedenie. Mezhdunarodnye otnosheniya [Science Journal of Volgograd State University. History. Area Studies. International Relations], 2019, vol. 24, no. 3, pp. 47-57. (in Russian). DOI: https://doi.org/10.15688/ jvolsu4.2019.3.4

Дата поступления статьи: 08.02.2019

ББК 63.2 Дата принятия статьи: 07.05.2019

\section{КЛИМАТИЧЕСКИЙ ОПТИМУМ КАК ФАКТОР КРИЗИСА ЭКОНОМИКИ СТЕПНЫХ НОМАДОВ В IV В. Н. э. ${ }^{1}$}

\author{
Михаил Васильевич Кривошеев
}

Волгоградский государственный университет, г. Волгоград, Российская Федерация 


\section{Александр Владимирович Борисов}

Институт физико-химических и биологических проблем почвоведения РАН, г. Пущино, Российская Федерация

Аннотация. На большей части территории распространения позднесарматской культуры памятники IV в. практически отсутствуют. Это может быть связано как со сложностями их выделения и отсутствием четких хроноиндикаторов, так и с оттоком кочевников из степной зоны. Возможно, на уменьшение кочевого населения в IV в. повлияли неблагоприятные условия для кочевого скотоводства. Данные палеопочвоведения позволяют реконструировать экологическую ситуацию в сухих и пустынных степях в первые века нашей эры. Начальный этап позднесарматской эпохи (вторая половина II - первая половина III вв. н. э.) отмечен аридными условиями с холодными малоснежными зимами, что благоприятно для ведения кочевого скотоводства в степной зоне. Во второй половине III - на рубеже III-IV вв. отмечаются процессы гумидизации увеличение увлажненности климата, что отражается на экологической ситуации в степи: высокий травостой, обводненность местности. Такая ситуация является оптимальной для выпаса скота в летний период. Однако зимой увеличение увлажненности сопровождается частыми оттепелями, дождями, туманами, сменяющимися периодами похолодания и связанными с этим обильными снегопадами, метелями, гололедом, обледенением травы, формированием ледяной корки и увеличением мощности снегового покрова. В этих условиях растет число невыпасных дней и, как следствие, болезни и ослабление скота вплоть до полной потери стада, за которыми следует гибель населения. Процессы гумидизации в первую очередь отразились на климате в Южном Приуралье и в финале III в. н. э. достигли волго-донских степей. Это могло стать причиной оттока позднесарматского населения из Южного Приуралья в районы Поволжья. В IV в. н. э. степи от Приуралья до Нижнего Дона практически обезлюдили. Начавшийся гумидный период, неблагоприятный для кочевого хозяйства, положительным образом отразился на оседло-земледельческих обществах. Раннеаланская культура Центрального Предкавказья демонстрирует динамику активного развития на всем протяжении позднесарматского периода, в том числе в IV в. н. э. Продолжительность данного гумидного периода оценить сложно, однако в гуннскую эпоху степи оставались практически не заселенными, о чем свидетельствует незначительное количество памятников этого времени. Вклад авторов. М.В. Кривошеевым проведены анализ и интерпретация письменных и археологических источников, А.В. Борисовым - палеопочвенных данных и реконструкция климатической ситуации.

Ключевые слова: сарматы, позднесарматская культура, почвоведение, экологическая ситуация, аридизация, гумидизация.

Цитирование. Кривошеев М. В., Борисов А. В. Климатический оптимум как фактор кризиса экономики степных номадов в IV в. н. э. // Вестник Волгоградского государственного университета. Серия 4, История. Регионоведение. Международные отношения. -2019. - Т. 24, № 3. - С. 47-57. - DOI: https://doi.org/10.15688/ jvolsu4.2019.3.4

Введение. Современная хронология сарматских памятников финала раннего железного века традиционно признает конец IV в. н. э. окончанием позднесарматской культуры. Такая датировка обусловлена историографической традицией, связанной с упоминанием Аммианом Марцеллином появления гуннов на границах дунайского лимеса в 370-х гг. и тезисом о том, что аланы-танаиты, обитавшие на Дону, были ими разгромлены и частично включены в гуннскую орду [2, XXXI, 3.1]. Традиционность обозначения верхней даты позднесарматской культуры концом IV в. н. э. также связана с высокой унифицированностью погребального обряда. Основные признаки не претерпевают серьезных изменений на протяжении существования культуры. В связи с этим, нередко при отсутствии четких хроноиндикаторов, бывает сложно отнести конкретный комплекс к начальному или финальному этапу культуры.

На этапе формирования позднесарматской культуры во второй половине II в. н. э. в районах Нижнего Поволжья и Нижнего Дона новое кочевое сообщество испытывало достаточно серьезное влияние традиций предшествующего среднесарматского населения. Однако к началу III в. н. э. признаки среднесарматской культуры в погребальном обряде были практически нивелированы позднесарматской традицией [15]. В Южном Приуралье, где среднесарматских памятников обнаружено значительно меньше, чем в других регионах, позднесарматская культура пред- 
ставлена в наиболее чистом виде с момента появления [22].

Современный взгляд на проблему не позволяет однозначно установить общую финальную дату позднесарматской культуры для разных регионов. В.Ю. Малашев, проведя анализ памятников второй половины III - IV в. н. э., пришел к выводу, что нет оснований говорить о существовании позднесарматской культуры в IV в. н. э. для всей территории ее первоначального распространения. В Южном Приуралье автор ограничил ее завершение не позднее второй половины третьего столетия [21; 22]. Ситуация может объясняться как отсутствием уверенных хроноиндикаторов IV в. н. э. в южноуральских памятниках, так и оттоком населения с этой территории в лесостепную зону Южного Приуралья или в район Приаралья [21, с. 50].

На территории Заволжья к IV в. н. э. относятся лишь два погребения Сусловского могильника [28].

Волго-Донское междуречье для периода второй половины III - IV в. н. э. не являлось единым культурно-политическим пространством. В это время здесь складываются два кочевых объединения, одно из которых занимало астраханское правобережье Волги, сохраняя традиции позднесарматской культуры. Второе связано с группой памятников в Т-образных катакомбах, которые ассоциируются с аланами-танаитами и распространены преимущественно на территории Нижнего Дона и в северной части Волго-Донского междуречья вплоть до верховий р. Медведицы [14].

Появление центрально-кавказского населения в середине III в. н. э. в низовьях Дона разрушило культурное единство позднесарматского мира второй половины II - первой половины III в. н. э. от Зауралья до Приазовья. В течение второй половины III в. н. э. наблюдается сосуществование новых катакомбных традиций и позднесарматского обряда, отождествляемого с погребениями в подбойных могилах. K IV в. н. э. подбои практически исчезают под влиянием новых традиций [5; 21, с. 49]. Такая ситуация позволила В.Ю. Малашеву вполне справедливо отказать захоронениям в Т-образных катакомбах в принадлежности к позднесарматской культуре. Этот обряд не имеет корней в позднесарматской по- гребальной традиции и генетически связан с аланской культурой Северного Кавказа [21, c. 50]. Нижнедонская группа памятников второй половины III - IV в. н. э. формируется на двухкомпонентной культурной основе: позднесарматской и аланской при доминанте последней, приведшей к исчезновению подбойных могил в IV в. н. э. [5, с. 85 ; 8, с. $20 ; 25]$. Аналогичные процессы культурогенеза наблюдались на этапе формирования позднесарматской культуры в Волго-Донском междуречье во второй половине II в. н. э. в условиях длительного сохранения среднесарматских погребальных традиций и постепенном их исчезновении к началу III в. н. э. под влиянием позднесарматских обрядовых норм [16].

K IV в. н. э. на Нижнем Дону относится значительно меньше захоронений, чем ко второй половине III в. н. э. Однако они четко идентифицируются по вещевому материалу и представлены в подавляющем большинстве случаев катакомбами. В северной части Волго-Донского междуречья культурно-этническая ситуация повторяет обстановку на Нижнем Дону. Известные памятники в бассейне p. Медведицы сочетают как катакомбные захоронения, так и погребения в подбоях и датируются преимущественно второй половиной III в. н. э. [14, с. 100].

На территории Северного Причерноморья кочевнические памятники второй половины III - IV в. н. э. немногочисленны. Катакомбные могилы близки нижнедонским памятникам этого периода. Связывать их с позднесарматской культурой, как и нижнедонские, вряд ли правомочно [21, с. 48-49].

Таким образом, исключая нижнедонские и северопричерноморские памятники второй половины III - IV в. н. э. из позднесарматских древностей, мы наблюдаем серьезнейшие изменения ситуации в степях Урало-Поволжья, связанные с резким уменьшением, практически исчезновением сарматских захоронений, датируемых IV в. н. э. В первой половине III в. н. э., в период расцвета позднесарматской культуры, она приобретает единообразие на всей территории распространения. В это время формируются два политических центpa: в Южном Приуралье и на Нижнем Дону. Процесс оформления элит демонстрирует богатые позднесарматские захоронения типа 
Лебедевских, Бердянки в Южном Приуралье [4; 22; 23], погребения могильников Валовый I, Центральный и др. на Нижнем Дону [7]. В Нижнем Подонье эти процессы были прерваны появлением населения центрально-кавказского происхождения. В Южном Приуралье мы не наблюдаем культурных изменений на протяжении всего III в. н. э. Тем не менее к концу III - началу IV в. н. э. на огромной территории урало-поволжских и нижнедонских степей практически исчезают курганы кочевников, что может быть связано с сокращением населения в степи. Одной из возможных причин обезлюдивания степи в IV в. н. э. могли стать изменения экологической ситуации в регионе.

\section{Материал и методика исследования.} Работы по реконструкции динамики природно-климатических условий на основе данных археологического почвоведения проводятся более сорока лет. Для эпохи раннего железного века степей Юго-Восточной Европы накоплен огромный объем материала, преимущественно на сарматских памятниках Нижнего Поволжья, Нижнего Подонья, Южного Приуралья [10; 26; 27]. Результатом обобще- ния имеющихся данных стала следующая схема изменений климатических условий в Нижневолжском регионе в период конца I тыс. до н. э. - начала I тыс. н. э., разработанная В.А. Демкиным (см. рисунок, $A$ ).

В свете полученных сведений вековая динамика степени увлажненности климата, основанная на палеопочвенных данных, представляется в следующем виде [10, с. 52]:

- период со второй половины II в. до н. э. по I в. н. э. - повышенные нормы осадков, которые могут рассматриваться как микроплювиальный период;

- конец I в. н. э. - первая половина II в. н. э. - постепенное усиление аридизации климата и снижение нормы зимних осадков;

- II в. н. э. - первая половина III в. н. э. аридный период с резким снижением нормы зимних осадков;

- вторая половина III в. н. э. - начало гумидизации и увеличение количества зимних осадков;

- конец III в. н. э. - IV в. н. э. - плювиальный период с максимально высокими нормами осадков.

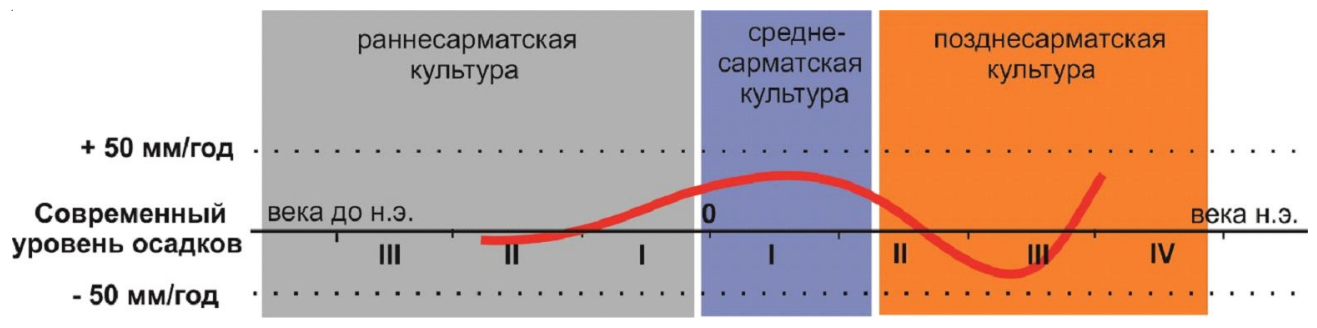

A

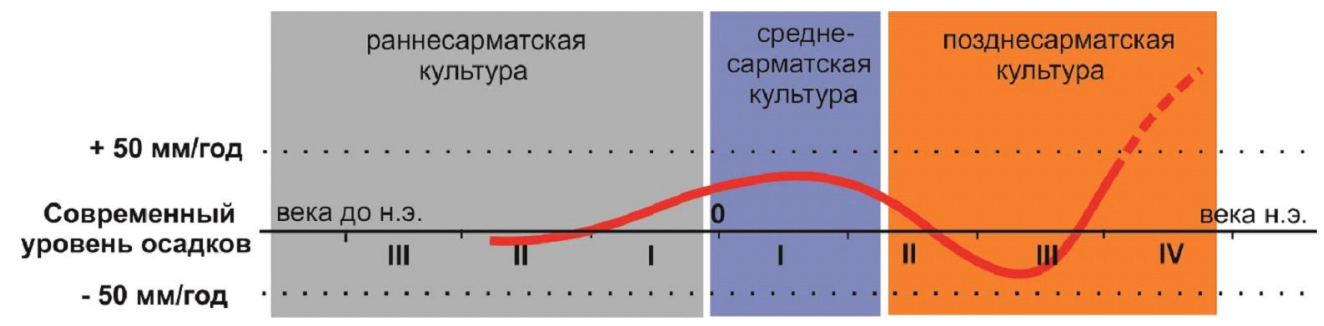

Б

Изменение атмосферной увлажненности в степной зоне Нижнего Поволжья в конце I тыс. до н. э. - начала I тыс. н. э.:

$A$ - сценарий, предлагаемый В.А. Демкиным и соавторами [10];

$B$ - предполагаемый авторами сценарий развития климата в финале позднесарматского времени

Changes in atmospheric humidity in the steppe zone of the Lower Volga region in the end of the $1^{\text {st }}$ millennium $\mathrm{BC}$ - the beginning of the $1^{\text {st }}$ millennium $\mathrm{AD}$ :

A - scenario proposed by V.A. Demkin and co-authors [10];

Б - climate developing scenario in the final of the Late Sarmatian time assumed by the authors 
К сожалению, климатические условия IV в. н. э. практически не исследованы по палеопочвенным данным в силу чрезвычайно малого количества памятников этого времени. Мы можем уверенно говорить лишь о том, что на позднесарматское время (это вторая половина - конец ІІІ в. н. э.) пришелся переломный момент, связанный с изменением увлажненности. Именно в это время начинается период гумидизации - устойчивого роста количества осадков - после предшествовавшего аридного эпизода, имевшего место во II первой половине III в. н. э. Так или иначе, к концу III - началу IV в. н. э. по всему исследованному региону отмечается установление более гумидных условий почвообразования. В целом период с конца III в. н. э., включая весь IV в. н. э., предложено рассматривать как «позднесарматский микроплювиал» [10, с. 49-52].

Анализ материала. Для того чтобы понять суть процессов аридизации и гумидизации, реконструируемых на основании палеопочвенных данных, следует рассмотреть, что происходит в почве при том или ином сценарии изменения климата.

В степной зоне основным фактором, определяющим климат холодного времени года, являлась устойчивость зимнего антициклона $[1$, c. 92]. В условиях мощного азиатского антициклона зимой устанавливается холодная сухая погода с малой мощностью снегового покрова или его полным отсутствием. В весенний период не происходит промачивания почвы, не вымываются соли, не формируются сегрегационные формы карбонатных аккумуляций. В условиях малой весенней влагозарядки наблюдается угнетение растительного покрова, уменьшение запасов гумуса и магнитной восприимчивости. Изреженный растительный покров способствует усилению эрозии и дефляции почв. Все эти признаки указывают на развитие аридизации $[9$, с. 51; 31]. Характерно, что в данные периоды создаются максимально комфортные условия для зимнего выпаса скота - основы экономики древних обществ. Именно такие условия сформировались в степной зоне во второй половине II в. н. э. и существовали на протяжении первой половины III в. н. э.

Обратный процесс на территории сухих и пустынных степей - гумидизация - наблю- дается при ослаблении зимнего антициклона и увеличении количества осадков. При этом в результате высоких норм осадков в зимний период вымываются токсичные для растений соли, создаются благоприятные условия для роста растений, чувствительных к засоленности почвы. В самой почве при этом будет происходить накопление гумуса, рост гумусового горизонта, вымывание водорастворимых солей в нижнюю часть почвенного профиля или за его пределы, снижение глубины вскипания, формирование крупной хорошо выраженной белоглазки, увеличение магнитной восприимчивости в верхних горизонтах и т. д. Иными словами, при палеопочвенных реконструкциях этот период будет диагностироваться как период гумидизации.

Обсуждение. Парадокс ситуации заключается в том, что на фоне оптимизации природных условий и расцвета (в прямом и переносном смысле) степи, резко ухудшаются условия для реализации традиционной хозяйственной модели ранних кочевников. В этот период наблюдаются частые зимние оттепели, дожди, туманы, за которыми следуют похолодание и связанные с этим обильные снегопады, метели, гололед, обледенение травы, формирование ледяной корки и увеличение мощности снегового покрова [9, с. 51]. В таких условиях увеличивается число невыпасных дней. Следствием становятся болезни и ослабление скота вплоть до полной потери стада, за которым следует гибель населения. Такие условия имели место в пустынно-степной зоне в начале поздней бронзы [3, с. 56]. Мы полагаем, что аналогичный сценарий начал реализовываться в Нижневолжском регионе во второй половине III в. н. э. Поэтому, если предположить дальнейшее развитие климатической ситуации в сторону гумидизации (см. рисунок, Б), то можно рассматривать экологический фактор как одну из причин отсутствия памятников позднесарматской культуры IV в. в урало-поволжских степях.

Что касается соседних регионов, то здесь также отмечается увеличение увлажненности, но с некоторыми характерными отличиями. Так, по данным О.С. Хохловой и А.А. Хохлова, на протяжении позднесарматского времени, то есть второй половины II III в. н. э., преобладали влажные и холодные 
условия [29, с. 108]. При этом авторы допускают, что процесс смены аридных условий гумидными в Южном Приуралье мог начаться даже несколько раньше: «...на переходе от средне- к позднесарматскому времени или в начале позднесарматского времени сухие условия сменились влажными» [29, с. 106]. Эти наблюдения позволяют предположить более ранние по сравнению с волго-донскими степями сроки начала гумидизации в Приуралье в позднесарматское время. В целом реконструкция динамики палеопочвенных процессов в первые века н. э. для данного региона затруднена ввиду небольшого количества памятников среднесарматского времени.

Косвенным фактом климатических изменений в степях Восточной Европы, отразившихся в первую очередь в Южном Приуралье, являются следы миграций позднесарматского населения, которые можно назвать внутренними. Как уже упоминалось выше, в начале III в. н. э. позднесарматская культура вырабатывает единообразные традиции для всех регионов распространения. К этому времени, помимо унификации погребального обряда наблюдаются и устойчивые экономические связи на этой территории. Например, керамика из производственных центров Северного Кавказа, ставших в этот период основными поставщиками керамической посуды в степь, распространяется не только в Волго-Донском регионе, но и в Южном Приуралье [22; 23]. Единые типы ременной гарнитуры, узды, вооружения характерны для всей культуры $[6 ; 20]$.

После разрушения Танаиса и меотских поселений на Дону в середине III в. н. э. в погребениях Волго-Донского региона появляются некоторые типы инвентаря, позволяющие четко обозначить середину III в. н. э. как хронологическую границу между двумя основными этапами позднесарматской культуры [17], в погребениях второй половины III в. н. э. в Нижнем Поволжье и на Нижнем Дону - лепные керамические формы, более характерные для южноуральских памятников. Появление южноуральской лепной посуды в волго-донских степях может свидетельствовать о движении позднесарматского населения из Южного Приуралья в Волго-Донской регион в свя- зи с началом периода неблагоприятных природно-экологических условий.

Еще одним аргументом правомочности предлагаемой палеоэкологической реконструкции может быть история развития раннеаланской культуры Северного Кавказа, этапы которой достаточно хорошо разработаны [11; 19]. Ее формирование завершается ко второй половине II в. н. э. Период наивысшего расцвета раннеаланской культуры связан с III в. н. э., что может быть отражением процесса гумидизации климата и, соответственно, повышением урожайности в регионе. В середине ІІІ в. н. э., вероятно, ввиду высокой демографической нагрузки в Центральном Предкавказье, наблюдается несколько миграционных волн из этого региона как на восток, до северных районов Дагестана, так и на запад, в степи Нижнего Подонья, где сформировались племена аланов-танаитов. Последующие миграции раннеаланского населения, относящиеся к IV в. н. э., связаны с дальнейшей экспансией на территории Кавказа, до Южного Дагестана [11, с. 162; 18; 24], но уже не в степные районы, где в это время, вероятно, климатическая ситуация была неблагоприятной.

Заключение. На основании анализа культурно-исторических событий и палеопочвенных реконструкций климатической ситуации в степях Восточной Европы в финале раннего железного века можно сделать следующие предположения об их взаимосвязи. В волго-донских степях аридизация климата II-III вв. н. э. создала весьма благоприятные условия для жизни ранних кочевников. Холодные сухие зимы в аридные периоды позволяли успешно реализовывать характерную для них хозяйственную модель, основанную на круглогодичном содержании скота на подножном корму. В таких условиях формировалась позднесарматская культура, достигнув расцвета в первой половине III в. н. э.

Гумидизация климата, начавшаяся в Южном Приуралье во второй половине III в. н. э., охватившая волго-донские степи в конце III начале IV в. н. э., повлекла за собой серьезные последствия для кочевников позднесарматского времени. Неустойчивая зимняя погода с обильными снегопадами, оттепелями и похолоданиями могла привести к резкому возрастанию числа невыпасных дней зимой, 
что ставило под угрозу выживание стада и, соответственно, самих кочевников. Такие климатические условия могли стать одной из причин сокращения населения в степи в IV в. н. э.

Проведенный анализ позволяет сделать предположение, что в IV в. н. э. в волго-донских степях сложились природные условия, исключающие либо значительно затрудняющие реализацию традиционной хозяйственной модели ранних кочевников.

В описанных критических для кочевого скотоводства условиях гумидизации вполне очевидным выходом могла быть откочевка зимой в более южные районы степи, где традиционно располагались зимники. Однако и там, в условиях повышенной увлажненности, обильный снежный покров мог стать серьезным препятствием для выпаса скота. Например, на Северном Кавказе позднесарматское время ознаменовалось активизацией роста ледников, указывающей на заснеженность и в предкавказской зоне [30].

Насколько длительным оказался период гумидизации в степях Восточной Европы, судить сложно. Хорошо известно только, что период нашествия с востока гуннской орды в последней четверти IV в. н. э. оставил крайне небольшое количество археологических свидетельств [13, с. 111-130]. Учитывая сходство хозяйственных моделей позднесарматских и гуннских племен, можно предположить, что в конце IV в. Южное Приуралье и волгодонские степи не представляли интереса для кочевников-скотоводов. Одной из причин могли быть продолжавшиеся неблагоприятные экологические условия, связанные с высокой гумидизацией климата. Отсутствие зимних пастбищ не позволяло населению задерживаться в степи и влекло на запад, где гумидизация была не столь интенсивной, и в более обводненные лесостепные районы, где существовала возможность зимнего выпаса скота в поймах рек [12] с использованием кустарников и подлеска в качестве грубых кормов.

\section{ПРИМЕЧАНИЕ}

${ }^{1}$ Работа выполнена в рамках Государственного задания Минобрнауки РФ (проект № 33.2830.2017/4.6 «Юг России в эпоху раннего железного века: диалог культур Восток - Запад»).
The work was carried out within the State task of the Ministry of Science and Higher Education of the Russian Federation (project no. 33.2830.2017/4.6 "South of Russia in the Early Iron Age: Dialogue of Cultures East - West").

\section{СПИСОК ЛИТЕРАТУРЫ}

1. Агроклиматические ресурсы Калмыцкой АССР. - Л. : Гидрометиздат, 1974. - 124 с.

2. Аммиан Марцеллин. Римская история / Аммиан Марцеллин. -СПб. : Алетейя, 2000. -576 c.

3. Аридизация климата в пустынно-степной зоне: причины, формы проявления и влияние на жизнь древнего населения / А. В. Борисов, М. В. Ельцов, С. Н. Удальцов, А. В. Бухонов // Вестник Волгоградского государственного университета. Серия 4, История. Регионоведение. Международные отношения. - 2018. - Т. 23, № 3. - С. 52-62. - DOI: https:// doi.org/10.15688/jvolsu4.2018.3.5.

4. Багриков, Г. И. Открытие гробниц в Западном Казахстане (II-IV и XIV вв.) / Г. И. Багриков, Т. Н. Сенигова // Известия АН КазССР. Серия «Общественные науки». - 1968. - № 2. - С. 71-89.

5. Безуглов, С. И. Аланы-танаиты: экскурс Аммиана Марцеллина и археологические реалии / С. И. Безуглов // Историко-археологические исследования в г. Азове и на Нижнем Дону в 1989 г. Азов : Изд-во Азов. краевед. музея, 1990. - Вып. 9. C. $80-87$.

6. Безуглов, С. И. Позднесарматские мечи (по материалам Подонья) / С. И. Безуглов // Сарматы и их соседи на Дону. - Ростов н/Д : Терра, 2000. C. 169-193.

7. Безуглов, С. И. Позднесарматские погребения в устье Дона (курганный могильник Валовый I) / С. И. Безуглов, В. П. Глебов, И. Н. Парусимов. - Ростов н/Д : Медиа-Полис, 2009. - 126 с.

8. Безуглов, С. Могильник Журавка и финал позднесарматской эпохи в Правобережном Подонье / С. Безуглов, А. Захаров // Известия Ростовского областного музея краеведения. - Ростов н/Д : Ростов. кн. изд-во, 1988. - Вып. 5. - С. 5-28.

9. Борисов, А. В. Аридизация: формы проявления и влияние на население степной зоны в бронзовом веке / А. В. Борисов, Р. А. Мимоход // Российская археология. -2017 . - № 2. - С. 48-60.

10. Волго-Донские степи в древности и средневековье (по материалам почвенно-археологических исследований)/ В. А. Демкин, А. В. Борисов, Т. С. Демкина, Т. Э Хомугова, Б. Н. Золотарева, Н. Н. Каширская, C. Н. Удальцов, М. В. Ельцов. - Пущино : SYNCHROBOOK, 2010. $-120 \mathrm{c}$.

11. Габуев, Т. А. Памятники ранних алан центральных районов Северного Кавказа / Т. А. Габу- 
ев, В. Ю. Малашев // Материалы и исследования по археологии России (МИАР). - М. : Таус, 2009. № $11 .-468 \mathrm{c}$.

12. Гак, Е. И. Сезонность поселений среднедонской катакомбной культуры: ландшафтно-экологическая модель / Е. И. Гак, А. В. Борисов // Российская археология. - 2017. - № 1. - С. 19-33.

13. Засецкая, И. П. Культура кочевников южнорусских степей в гуннскую эпоху (конец IV-V вв.) / И. П. Засецкая. - СПб. : Эллипс Лтд, 1994. - 224 с.

14. Кривошеев, М. В. Волго-Донское междуречье в середине III-IV вв. н. э. Этноисторические проблемы / М. В. Кривошеев // Проблемы археологии Нижнего Поволжья : материалы V Международной Нижневолжской археологической конференции (15-18 нояб. 2016 г.). - Элиста : Изд-во Калмыцк. ун-та, 2016. - С. 100-103.

15. Кривошеев, М. В. Позднесарматская культура междуречья Волги и Дона. Проблема становления и развития / М. В. Кривошеев, А. С. Скрипкин // Российская археология. -2006.-№ 1. - С. 124-136.

16. Кривошеев, М. В. Формирование и развитие позднесарматской культуры в Нижнем Поволжье (по данным погребального обряда) / М. В. Кривошеев, А. С. Скрипкин // Погребальный обряд ранних кочевников Евразии : материалы VII Междунар. науч. конф. (г. Ростов-на-Дону, Кагальник, 11-15 мая 2011 г.). - Ростов н/Д : ЮНЦ PAH, 2011. - C. 75-85.

17. Кривошеев, М. В. Хроноиндикаторы середины III-IV вв. н. э. из степных памятников Волго-Донского региона / М. В. Кривошеев, В. Ю. Малашев // Античная цивилизация и варварский мир Понто-Каспийского региона : материалы Всерос. науч. конф. с междунар. участием, посвящ. 70-летнему юбилею Б.А. Раева (г. Кагальник, 20-21 окт. 2016 г.). - Ростов н/Д : ЮНЦ РАН, 2016. - С. 138-147.

18. Малашев, В. Ю. Аланская культура Северного Кавказа: проблема ранней государственности у населения региона во II-IV вв. н. э. / В. Ю. Малашев // Краткие сообщения Института археологии. 2014. - Вып. 234. - С. 72-83.

19. Малашев, В. Ю. Культурная ситуация в центральных районах Северного Кавказа во IIIV вв. н. э. / В. Ю. Малашев // Три четверти века. Д.В. Деопику - друзья и ученики : сб. ст. - М. : Памятники исторической мысли, 2007. - С. 487-501.

20. Малашев, В. Ю. Периодизация ременных гарнитур позднесарматского времени / В. Ю. Малашев // Сарматы и их соседи на Дону. - Ростов н/Д : Teppa, 2000. - С. 194-232.

21. Малашев, В. Ю. Позднесарматская культура: верхняя хронологическая граница / В. Ю. Малашев // Российская археология. - 2009. - № 1. C. 47-52.
22. Малашев, В. Ю. Позднесарматская культура Южного Приуралья во II-III вв. н. э. : дис. ... канд. ист. наук / Малашев Владимир Юрьевич. М., 2013. $-301 \mathrm{c}$.

23. Малашев, В. Ю. Степное население Южного Приуралья в позднесарматское время / В. Ю. Малашев, Л. Т. Яблонский. - М. : Вост. лит., 2008. - 365 c.

24. Малашев, В. Ю. Страна маскутов в Западном Прикаспии. Курганные могильники Прикаспийского Дагестана III-V вв. н. э. / В. Ю. Малашев, М. С. Гаджиев, Л. С. Ильюков. - Махачкала : Мавраевъ, 2015. - $452 \mathrm{c}$.

25. Малашев, В. Ю. Центральные районы Северного Кавказа в позднесарматское время / В. Ю. Малашев // Становление и развитие позднесарматской культуры (по археологическим и естественнонаучным данным) : материалы семинара Центра изучения истории и культуры сарматов.- Волгоград : Изд-во ВолГУ, 2010. - Вып. III. C. $117-142$.

26. Палеопочвы и климат степей Нижнего Поволжья в I-IV вв. н. э. / В. А. Демкин, Т. С. Демкина, А. О. Алексеев, Т. Э. Хомутова, Б. Н. Золотарева, Н. Н. Каширская, С. Н. Удальцов, Т. В. Алексеева, А. В. Борисов, Е. В. Демкина, А. Н. Журавлев. Пущино : ОНТИ ПНЦ РАН, 2009. - 96 с.

27. Развитие почв Нижнего Поволжья за историческое время / В. А. Демкин, М. В. Ельцов, А. О. Алексеев, Т. В. Алексеева, Т. С. Демкина, А. В. Борисов // Почвоведение. - 2004. - № 12. C. $1486-1497$.

28. Скрипкин, А. С. Две бронзовые пряжки из Сусловского могильника / А. С. Скрипкин // Coветская археология. - 1976. - № 3. - С. 325-327.

29. Хохлова, О. С. Палеопочвенное изучение курганов могильника Покровка 10 и палеоклиматические реконструкции для РЖВ Южного Приуралья / О. С. Хохлова, А. А. Хохлов // Степное население Южного Приуралья в позднесарматское время: по материалам могильника Покровка 10 / В. Ю. Малашев, Л. Т. Яблонский. - М. : Вост. лит., 2008. - C. 101-113.

30. Шнитников, А. В. Изменчивость общей увлажненности материков Северного полушария / А. В. Шнитников // Записки географического общества Союза ССР. - М. : АН СССР, 1957. $-337 \mathrm{c}$

31. Borisov, A. Climate changes and soil evolution in desert steppe zone of Russian Plain during the Bronze Age / A. Borisov, N. Shishlina // International Multidisciplinary Scientific GeoConference Surveying Geology and Mining Ecology Management SGEM, SGEM 2017 Conference Proceedings. - 2017. - Vol. 17, iss. 32. - P. 77-84. DOI: $10.5593 /$ sgem 2017/32/S13.011. 


\section{REFERENCES}

1. Agroklimaticheskie resursy Kalmytskoy ASSR [Agro-Climatic Resources of the Kalmyk ASSR]. Leningrad, Gidrometizdat Publ., 1974. 124 p.

2. Ammianus Marcellinus. Rimskaya istoriya [Roman History]. Saint-Petersburg, Aleteya Publ., 2000. $576 \mathrm{p}$.

3. Borisov A.V., Eltsov M.V., Udaltsov S.N., Bukhonov A.V. Aridizatsiya klimata v pustynnostepnoy zone: prichiny, formy proyavleniya i vliyanie na zhizn drevnego naseleniya [Climate Aridization in the Desert-Steppe Zone: The Causes, Results and Impact on Life of the Ancient Population]. Vestnik Volgogradskogo gosudarstvennogo universiteta. Seriya 4, Istoriya. Regionovedenie. Mezhdunarodnye otnosheniya [Science Journal of Volgograd State University. History. Area Studies. International Relations], 2018, vol. 23, no. 3, pp. 52-62. DOI: https:// doi.org/10.15688/jvolsu4.2018.3.5.

4. Bagrikov G.I., Senigova T.N. Otkrytie grobnits v Zapadnom Kazakhstane (II-IV i XIV vv.) [The Discovery of the Tombs in Western Kazakhstan ( $2^{\text {nd }}$ $4^{\text {th }}$ and $14^{\text {th }}$ Centuries]. Izvestiya AN KazSSR. Seriya "Obshchestvennye nauki", 1968, no. 2, pp. 71-89.

5. Bezuglov S.I. Alany-tanaity: ekskurs Ammiana Martsellina i arkheologicheskie realii [The Tanaite Alans: Ammianus Marcellinus' Account and Archaeological Reality]. Istoriko-arkheologicheskie issledovaniya v g. Azove i na Nizhnem Donu v 1989 g. [Historical and Archaeological Research in Azov and the Lower Don in 1989]. Azov, Izd-vo Azovskogo Kraevedcheskogo muzeya, 1990, iss. 9, pp. 80-87.

6. Bezuglov S.I. Pozdnesarmatskie mechi (po materialam Podonya) [The Late Sarmatian Swords (Exemplified by the Don Region)]. Sarmaty i ikh sosedi na Donu. Materialy i issledovaniya po arkheologii Dona [Sarmatians and Their Neighbours in the Don Region. Materials and Research on Don Archaeology]. Rostov-on-Don, Terra Publ., 2000, pp. 169-193.

7. Bezuglov S.I., Glebov V.P., Parusimov I.N. Pozdnesarmatskie pogrebeniya $v$ ustye Dona (kurgannyy mogilnik Valovyy I) [Late Sarmatian Burials in the Mouth of the Don River (Valovyy I Burial Mound)]. Rostov-on-Don, Media-Polis Publ., 2009. $126 \mathrm{p}$.

8. Bezuglov S., Zakharov A. Mogilnik Zhuravka i final pozdnesarmatskoy epokhi v Pravoberezhnom Podone [Zhuravka Burial Ground and the Final of the Late Sarmatian Epoch in the Right-Bank Lower Don Region]. Izvestiya Rostovskogo oblastnogo muzeya kraevedeniya. Rostov-on-Don, Rostovskoe knizhnoe izdatelstvo, 1988, iss. 5, pp. 5-28.

9. Borisov A.V., Mimokhod R.A. Aridizatsiya: formy proyavleniya i vliyanie na naselenie stepnoy zony v bronzovom veke [Aridization: Forms and Impact on the Population of the Desert Steppe Zone in the Bronze Age]. Rossiyskaya arkheologiya [Russian Archaeology], 2017, no. 2, pp. 48-60.

10. Demkin V.A., Borisov A.V., Demkina T.S., Khomutova T.E., Zolotareva B.N., Kashirskaya N.N., Udaltsov S.N., Eltsov M.V. Volgo-Donskie stepi $v$ drevnosti $i$ srednevekove (po materialam pochvenno-arkheologicheskikh issledovaniy) [Volga-Don Steppes in Ancient Times and in the Middle Ages (Based on the Materials of Soil and Archaeological Research)]. Pushchino, SYNCHROBOOK Publ., 2010. 120 p.

11. Gabuev T.A., Malashev V.Yu. Pamyatniki rannikh alan tsentralnykh rayonov Severnogo Kavkaza [Early Alanian Sites of the Central Regions of the North Caucasus]. Materialy i issledovaniya po arkheologii Rossii (MIAR) [Materials and Research on Archaeology of Russia]. Moscow, Taus Publ., 2009, no. $11.468 \mathrm{p}$.

12. Gak E.I., Borisov A.V. Sezonnost poseleniy srednedonskoy katakombnoy kultury: landshaftnoekologicheskaya model [Seasonal Settlements of the Middle Don Catacomb Culture: A LandscapeEcological Pattern]. Rossiyskaya arkheologiya [Russian Archaeology], 2017, no. 1, pp. 19-33.

13. Zasetskaya I.P. Kultura kochevnikov yuzhnorusskikh stepey $v$ gunnskuyu epokhu (konets $I V-V v v$.) [The Nomadic Culture in the Southern Russian Steppes During the Hun Epoch (the Late $4^{\text {th }}$ $5^{\text {th }}$ Centuries)]. Saint-Petersburg, Ellips LTD Publ., $1994.224 \mathrm{p}$.

14. Krivosheev M.V. Volgo-Donskoe mezhdureche v seredine III-IV vv. n. e. Etnoistoricheskie problemy[The Volga-Don Interfluve in the Middle of the $3^{\text {rd }}-4^{\text {th }}$ Centuries AD. Ethnohistorical Problems]. Problemy arkheologii Nizhnego Povolzhya: materialy $5^{\text {th }}$ Mezhdunarodnoy Nizhnevolzhskoy arkheologicheskoy konferentsii (1518 noyab. 2016g.) [Materials of the V International Lower Volga Archaeological Conference "Problems of Archaeology of the Lower Volga Region" (15-18 November 2016)]. Elista, Izd-vo Kalmytskogo universiteta, 2016. pp. $100-103$.

15. Krivosheev M.V., Skripkin A.S. Pozdnesarmatskaya kultura mezhdurechya Volgi i Dona. Problema stanovleniya i razvitiya [Late Sarmatian Culture of the Volga-Don Interfluve. The Problem of Formation and Development]. Rossiyskaya arkheologiya [Russian Archaeology], 2006, no. 1, pp. 124-136.

16. Krivosheev M.V., Skripkin A.S. Formirovanie i razvitie pozdnesarmatskoy kultury v Nizhnem Povolzhe (po dannym pogrebalnogo obryada) [The Formation and Development of the Late Sarmatian Culture in the Lower Volga Region (According to the Funeral Rite)]. Pogrebalnyy obryad rannikh kochevnikov Evrazii: materialy VII Mezhdunar. nauch. konf. (11-15 maya 
2011 g., g. Rostov-na-Donu, Kagalnik) [Funeral Rite of the Early Eurasian Nomads. Materials of the $7^{\text {th }}$ International Scientific Conference (Rostov-on-Don, Kagalnik, 11-15 May 2011)]. Rostov-on-Don, YuNTs RAN, 2011, pp. 75-85.

17. Krivosheev M.V., Malashev V.Yu. Chronoindikatory serediny III-IV vv. n.e. iz stepnykh pamyatnikov Volgo-Donskogo regiona [Chronological Indicators of the Middle of the $3^{\text {rd }}-4^{\text {th }}$ Centuries AD from the Steppe Archaeological Sites of the Volga-Don Region]. Antichnaya tsivilizatsiya $i$ varvarskiy mir Ponto-Kaspiyskogo regiona: materialy Vseros. nauch. konf. s mezhdunar. uchastiem, posvyashch. 70-letnemu yubileyu B.A. Raeva (g. Kagalnik, 20-21 oktyabrya 2016 g.) [Ancient Civilization and Barbaric World of the Ponto-Caspian Region. Proceedings of the AllRussian Academic Conference with International Participation Dedicated to B.A. Raev's $70^{\text {th }}$ Anniversary (Kagalnik, October 20-21, 2016)]. Rostov-on-Don, YuNTs RAN, 2016, pp. 138-147.

18. Malashev V.Yu. Alanskaya kultura Severnogo Kavkaza: problema ranney gosudarstvennosti u naseleniya regiona vo II-IVvv. n.e. [The Alanian Culture in the Northern Caucasus: The Question of the Early State Formations Among the Population of the Region in the $2^{\text {nd }}-4^{\text {th }} \mathrm{cc}$. AD]. Kratkie soobshcheniya Instituta arkheologii [Brief Communications of the Institute of Archaeology], 2014, iss. 234, pp. 72-83.

19. Malashev V.Yu. Kulturnaya situatsiya v tsentralnykh rayonakh Severnogo Kavkaza vo IIIV vv. n. e. [The Cultural Situation in the Central Regions of the North Caucasus in the $2^{\text {nd }}-4^{\text {th }}$ Centuries AD]. Tri chetverti veka. D.V. Deopiku - druzya $i$ ucheniki: sbornik statey [Three Quarters of a Century. To D.V. Deopik - Friends and Students. Collected Articles]. Moscow, Pamyatniki istoricheskoy mysli, 2007,pp. 487-501.

20. Malashev V.Yu. Periodizatsiya remennykh garnitur pozdnesarmatskogo vremeni [Periodizations of Belt Fittings of the Late Sarmatian Time]. Sarmaty $i$ $i k h$ sosedi na Donu [Sarmatians and Their Neighbours From the Don]. Rostov-on-Don, Terra Publ., 2000, pp. 194-232.

21. Malashev V.Yu. Pozdnesarmatskaya kultura: verkhnyaya khronologicheskaya granitsa [Late Sarmatian Culture: Upper Chronological Boundary]. Rossiyskaya arkheologiya [Russian Archaeology], 2009, no. 1, pp. 47-52.

22. Malashev V.Yu. Pozdnesarmatskaya kultura Yuzhnogo Priuralya vo II-III vv. n. e.: dis. ... kand. ist. nauk [Late Sarmatian Culture of the Southern Urals in the $2^{\text {nd }}-3^{\text {rd }}$ Centuries A.D. Cand. hist. sci. diss.]. Moscow, 2013. 301 p.

23. Malashev V.Yu., Yablonskiy L.T. Stepnoe naselenie Yuzhnogo Priuralya v pozdnesarmatskoe vremya [Steppe Population of the Southern Urals in the Late Sarmatian Time]. Moscow, Vostochnaya literatura Publ., 2008. 365 p.

24. Malashev V.Yu., Gadzhiev M.S., Ilyukov L.S. Strana maskutov v Zapadnom Prikaspii. Kurgannye mogilniki Prikaspiyskogo Dagestana III-Vvv. n. e. [Mascoutis Country in the Western Caspian Region. Burial Mounds of the Caspian Dagestan in the $3^{\text {rd }}-5^{\text {th }}$ Centuries BC]. Makhachkala, Mavraev Publ., 2015. 452 p.

25. Malashev V.Yu. Tsentralnye rayony Severnogo Kavkaza v pozdnesarmatskoe vremya [Central Regions of the North Caucasus in the Late Sarmatian Period]. Stanovlenie $i$ razvitie pozdnesarmatskoy kultury (po arkheologicheskim $i$ estestvennonauchnym dannym): Materialy seminara Tsentra izucheniya istorii $i$ kultury sarmatov [The Formation and Development of the Late Sarmatian Culture (Based on Archaeological and Natural Science Data). Materials of the Seminar of the Center for Studying History and Culture of the Sarmatians]. Volgograd, Izd-vo VolGU, 2010, iss. 3, pp. 117-142.

26. Demkin V.A., Demkina T.S., Alekseev A.O., Khomutova T.E., Zolotareva B.N., Kashirskaya N.N., Udaltsov S.N., Alekseeva T.V., Borisov A.V., Demkina E.V., Zhuravlev A.N. Paleopochvy i klimat stepey Nizhnego Povolzhya v I-IV vv. n.e. [Paleosoils and the Climate of the Steppes of the Lower Volga Region in the $1^{\text {st }}-4^{\text {th }}$ c. AD]. Pushchino, ONTI PNTs RAN, $2009.96 \mathrm{p}$.

27. Demkin V.A., Eltsov M.V., Alekseev A.O., Alekseeva T.V., Demkina T.S., Borisov A.V. Razvitie pochv Nizhnego Povolzhya za istoricheskoe vremya [Development of Soils of the Lower Volga Region in Historical Time]. Pochvovedenie [Eurasian Soil Science], 2004, no. 12, pp. 1486-1497.

28. Skripkin A.S. Dve bronzovye pryazhki iz Suslovskogo mogilnika [Two Bronze Buckles from Suslovskiy Burial Mound]. Sovetskaya arkheologiya, 1976, no. 3, pp. 325-327.

29. Khokhlova O.S., Khokhlov A.A. Paleopochvennoe izuchenie kurganov mogilnika Pokrovka 10 i paleoklimaticheskie rekonstruktsii dlya RZhV Yuzhnogo Priuralya [Paleosoil Studying of Barrows of Pokrovka 10 Burial Ground and Paleoclimatic Reconstructions for the Early Iron Age of the Southern Urals]. Malashev V.Yu., Yablonskiy L.T., eds. Stepnoe naselenie Yuzhnogo Priuralya $v$ pozdnesarmatskoe vremya: po materialam mogilnika Pokrovka 10 [Steppe Population of the Southern Urals in the Late Sarmatian Time. Based on the Materials of Pokhrovka 10 Burial Ground]. Moscow, Vostochnaya literatura Publ., 2008. pp. 101-113.

30. Shnitnikov A.V. Izmenchivost obshchey uvlazhnennosti materikov Severnogo polushariya [The Variability of the Total Humidity of the Continents of the Northern Hemisphere]. Zapiski 
М.В. Кривошеев, А.В. Борисов. Климатический оптимум как фактор кризиса экономики степных номадов

geograficheskogo obshchestva Soyuza SSR. [Notes of the Geographical Society of the USSR]. Moscow, AN SSSR, 1957. 337 p.

31. BorisovA., Shishlina N. Climate Changes and Soil Evolution in Desert Steppe Zone of Russian Plain
During the Bronze Age. International Multidisciplinary Scientific GeoConference Surveying Geology and Mining Ecology Management SGEM, SGEM 2017 Conference Proceedings, 2017, vol. 17, iss. 32, pp. 77-84. DOI: 10.5593/sgem2017/32/S13.01.

\section{Information about the Authors}

Mikhail V. Krivosheev, Candidate of Sciences (History), Head of the Laboratory of Archaeological Research, Volgograd State University, Prosp. Universitetsky, 100, 400062 Volgograd, Russian Federation, arhlab@volsu.ru,tyaf@mail.ru, https://orcid.org/0000-0003-4847-8209

Aleksandr V. Borisov, Candidate of Sciences (Biology), Head of the Laboratory of Archaeological Soil Science, Institute of Physical-Chemical and Biological Problems of Soil Science, Russian Academy of Sciences, Institutskaya St., 2, 142290 Pushchino, Moscow Region, Russian Federation, a.v.borisovv@gmail.com, https://orcid.org/0000-0001-5031-7477

\section{Информация об авторах}

Михаил Васильевич Кривошеев, кандидат исторических наук, заведующий лабораторией археологических исследований, Волгоградский государственный университет, просп. Университетский, 100, 400062 г. Волгоград, Российская Федерация, arhlab@volsu.ru, tyaf@mail.ru, https://orcid.org/0000-0003-4847-8209

Александр Владимирович Борисов, кандидат биологических наук, заведующий лабораторией археологического почвоведения, Институт физико-химических и биологических проблем почвоведения РАН, ул. Институтская, 2, 142290 г. Пущино, Российская Федерация, a.v.borisovv@gmail.com, https://orcid.org/0000-0001-5031-7477 